\title{
LA RATIO STUDIORUM COMO FORMADORA DE LA MENTALIDAD ESCOLÁSTICA COLOMBIANA
}

\author{
Édgar A. Ramírez \\ Universidad Santo Tomás
}

\section{Resumen}

La mentalidad escolástica desarrollada durante la Colonia sigue determinando los criterios educativos en Colombia y formando parte de la manera como los colombianos damos razón de nosotros mismos.

La ratio studiorum es la estrategia educativa que más influyó en la formación de la mentalidad escolástica en América Latina. La Compañía de Jesús la implementó en la Nueva Granada por medio de su Colegio en Santa Fe y posteriormente en la Academia Javeriana, derivada de aquél.

En la base de nuestra manera de interpretar la realidad sigue operando la lógica bipolar escolástica. Ésta continúa determinando nuestros criterios epistemológicos, éticos y estéticos, y nos impide el acceso a comprensiones más globales e integradoras. Por esto, es necesario que nos pensemos, hablando en términos pedagógicos, desde y para nosotros mismos, mediante categorías y metodologías que permitan comprendernos mejor y dar sentido a lo educativo frente a la realidad nacional.

\section{Palabras clave}

Filosofía, pedagogía, filosofía de la educación, escolástica, ratio studiorum.

\begin{abstract}
We depend on the colonial scholastic mentality more than what we are conscious about. Therefore, it is necessary to study how this mentality was formed and how it has affected our own understanding.
\end{abstract}


The ratio studiorum is the educative strategy that has most influenced the formation of the scholastic mentality in Latin America. The Jesuit Community implemented it in New Granada with the Jesuits' school in Santa Fe (founded in 1604 and which would be called "of San Bartolomé" since 1605) and in the Academy, later Javeriana University (1623).

In this mentality most of the leaders of our independence were formed and it has had a significant influence, still today, in the Colombian mentality.

\section{Index terms}

Philosophy, pedagogy, philosophy of education, scholastic, ratio studiorum.

\section{Introducción}

Tal vez una reflexión más profunda nos permitiría establecer hasta qué punto este modo de ser nos viene de que seguimos siendo en esencia la misma sociedad excluyente, formalista y ensimismada de la Colonia ${ }^{1}$.

Los colombianos dependemos de la mentalidad escolástica colonial más de lo que somos conscientes. Por esto, es tan necesario estudiar cómo se formó esta mentalidad y de qué manera incide en nuestra comprensión de nosotros mismos.

La ratio studiorum es la estrategia educativa que más influyó en la formación de la mentalidad escolástica en América Latina. La Compañía de Jesús la implementó en la Nueva Granada por medio de su Colegio en Santa Fe (fundado en 1604 y que se llamaría de San Bartolomé a partir de 1605), y en la Aca- demia, posterior Universidad Javeriana (1623), derivada de aquel.

En esta mentalidad se formó la mayoría de los próceres de nuestra independencia y tiene una influencia significativa, aún hoy, en la mentalidad colombiana ${ }^{2}$.

\section{1. ¿Qué es la ratio studiorum? ${ }^{3}$}

Ratio studiorum se denominó la ordenación de los estudios desarrollada por la Compañía de Jesús a partir de la experiencia espiritual y académica de San Ignacio y de los primeros jesuitas.

San Ignacio de Loyola fue un caballero "dado a las vanidades del mundo”, como decía de sí mismo; pero por una profunda y muy particular experiencia de Dios, decidió dedicar su vida al servicio de los demás, dejando plasmada esta experiencia en los Ejercicios espirituales. Servir eficazmente le exigía cua-

1 GARCÍA MÁRQUEZ, Gabriel. "Por un país al alcance de los niños”. Informe de la Misión de Ciencia, Educación y Desarrollo.

2 Por mentalidad se entiende un bien común que se transmite por la tradición. Hace referencia al "modo de pensar” de una generación; por esto, tiene un carácter social e impersonal. Al respecto, recomiendo ver: RAMÍREZ, E. "Posibilidades de la historia de las ideas y de las mentalidades para la filosofía latinoamericana”. En: Cuadernos de filosofía latinoamericana $\mathrm{n}^{\circ}$ 78-79, 2000.

3 Sobre el tema, recomiendo ver: RAMÍREZ, Édgar. Implementación de la Ratio Studiorum en el Colegio de San Bartolomé (1604 - 1767). 
lificarse. Por esto, comenzó a estudiar latín con niños de escuela, a pesar de que ya tenía más de treinta años. Esta búsqueda lo llevó por las universidades de Barcelona, Alcalá y Salamanca para terminar en la más reconocida institución escolar de la época: la Universidad de París (1528). Su gran experiencia académica le dio un conocimiento bastante amplio de los mejores métodos de estudio del momento.

La organización de la Compañía de Jesús y la formación de los nuevos jesuitas demandó que San Ignacio elaborara las Constituciones. En la parte IV de esta obra, San Ignacio prevé con rigor cómo debe educarse un escolar para alcanzar una formación humanística, filosófica y teológica como la que se espera de alguien que va a participar de los principales debates de su época, como el de la reforma protestante, por ejemplo. Éste fue el marco conceptual a partir del cual se organizaron los primeros colegios ${ }^{4}$ creados por la Compañía y se estructuró la ratio studiorum.

Las primeras instituciones educativas de los jesuitas, que tuvieron mucho éxito, exigieron unas directrices (Constituciones) comunes que se inscribieran en el "espíritu de la Compañía”. En este sentido, San Ignacio solicitó abrir entre los colegios creados una consulta sobre la forma como deberían organizarse; cada institución debía escribir y enviar a Roma las "relaciones" de sus experiencias educativas al respecto. Allí se recopilaba la información, se revisaba minucio- samente por los mejores expertos, se hallaban los elementos comunes y acordes con la espiritualidad, se solicitaba la iluminación divina para hallar lo más conveniente al servicio de los demás, y se devolvía a los colegios para su aplicación y estudio. Pasado un tiempo prudencial, se evaluaba la experiencia y se devolvían las conclusiones a Roma para volver a hacer el ejercicio anterior. Este proceso de construcción de la Ratio es una dinámica derivada del discernimiento espiritual ignaciano.

San Ignacio delegó la coordinación de este proceso en el P. Jerónimo Nadal, quien se constituyó en el primer y gran sistematizador de la Ratio studiorum. De esta manera, la Ratio duró 44 años en “construcción” hasta su publicación oficial el 8 de enero de 1599.

En la primera edición de la Ratio se habla de ella como el "método y programa de los estudios de la Compañía de Jesús”. Esta caracterización ha hecho que algunos la consideren apenas como un plan de estudios. En realidad, con el tiempo se fue consolidando como una pedagogía en cuanto dispone de una fundamentación antropológica (basada en el humanismo cristiano contrarre-formado), desarrolla una forma de explicar la educabilidad del ser humano (el "modo" jesuítico de proceder) y explicita una didáctica que se desprende de ella; didáctica derivada de la experiencia académica de San Ignacio y, en particular, del modus parisiensis (métodos de la Universidad de París).

$4 \quad$ Collegium, en el sentido renacentista del término, es un colegio universitario.

5 Cabe contar que hubo algunos ex alumnos sobresalientes de los jesuitas. Entre quienes fueron fruto de la Ratio studiorum en Europa se pueden mencionar figuras como las siguientes:

- Los españoles Lope de Vega (1562-1635), Pedro Calderón de la Barca (1600-1681) y Miguel de Cervantes (1549-1616).

- Los dramaturgos franceses Pierre Corneille (1606-1684) y J. B. Molliére (1622-1673).

- Los enciclopedistas Diderot, Voltaire, Montesquieu y Rousseau.

- El filósofo René Descartes (1596-1650).

- En las ciencias exactas sobresalieron el P. Cristóbal Klaus (1538-1612), P. Angel Secchi (1818-1878), P. Mateo Ricci (1552-1610), P. Edmundo de Villemarquée (1881-1939), P. Francisco Lana-Terzi (16311687). 
El éxito de los colegios de los jesuitas y de las universidades a las que dieron lugar se extendió por el mundo entero ${ }^{5}$. De esta manera, la Ratio se consolidó como la pedagogía más importante del mundo moderno occidental, particularmente porque involucraba una red de colegios y universidades orientada por un proyecto educativo común y bajo una dirección central.

La Ratio está estructurada en treinta conjuntos de reglas y normas que desarrollan minuciosamente cómo debe formarse un estudiante de un Colegio de la Compañía de Jesús. Para esto, determina los deberes de los responsables, enumera las actividades académicas y lúdicas cotidianas y explicita los criterios de evaluación de los procesos de formación.

Característica fundamental de la Ratio es la combinación de experiencias significativas de aprendizaje con la reflexión para deducir de allí mejores líneas de acción (como un proceso en el que interactúan experiencia, reflexión y acción). Ejemplo de ello pueden ser los permanentes ejercicios públicos de retórica y las "academias" por medio de los cuales el estudiante se veía en la obligación de preparar y desarrollar una posición personal sobre un tema, de exponerlo frente a otros con claridad y coherencia, de "defender" su posición personal por medio de la argumentación frente a las objeciones que le presentaban, y de rehacer su presentación si fuere necesario.

La Ratio dispuso de las metodologías propias de la época, como la lectio y la disputatio. Éstas exigían al profesor escribir sus clases ${ }^{6}$ para leerlas y explicarlas en el aula, y abrir un debate silogístico sobre ellas que permitiera la apropiación de los contenidos por parte de los estudiantes; todo esto en el marco de la doctrina de Santo Tomás para evitar los peligros del protestantismo, pero desde la perspectiva suareciana (de Francisco Suárez, S.J.) propia de los jesuitas? ${ }^{7}$.

Desarrolló metodologías propias que la caracterizaron, tal como la prelección y la repetición. La prelección consiste en una estrategia por medio de la cual el educador debe abrir un espacio de contextualización de cada actividad escolar en la que se identifica con claridad el sentido de la misma. La repetición consiste en una estrategia para reafirmar los conocimientos adquiridos. Atiende al principio ignaciano según el cual "no el mucho saber harta y satisface el ánima como el sentir y gustar las cosas internamente" (Anotaciones de los Ejercicios espirituales). Se trata de volver sobre lo alcanzado para reafirmarlo significativamente, como un ejercicio de metacognición.

El plan de estudios en la Ratio se organiza alrededor de los estudios de humanidades (latín, retórica, letras o literatura), filosofía (incluye lógica y matemática, física, ética y metafísica, psicología y matemática superior) y teología (dirigido especialmente a quienes buscaban el sacerdocio). Posteriormente se fueron abriendo estudios en ciencias para los estudiantes más aventajados. En nuestro caso, la jurisprudencia (cánones y leyes) y la medicina.

Pero quizás el aporte más significativo de la Ratio consistió en su esfuerzo por alcanzar la formación integral del estudiante. Con lo expuesto, claramente se puede afirmar que la educación jesuita no se reducía a lo espiritual o a lo académico (o a ese carácter espiri-

Muchos de estos textos se conservan y están pendientes de ser traducidos.

No se estudian aquí las otras perspectivas que tuvo la escolástica en la Nueva Granada: la dogmática de los dominicos ni la scotista de los franciscanos. Esto, porque la escolástica suareciana fue la que tuvo más influencia en el mundo académico colonial. 
tual de lo académico tan propio de la Compañía de Jesús). La Ratio atendía a la persona en su integralidad; de ello da cuenta la cantidad de actividades de aprendizaje previstas pensando en cada dimensión de la persona, pues abarcan tanto lo académico y espiritual como la formación del carácter, lo ético-moral, lo lúdico, lo corporal, lo estético, lo comunicativo y lo social.

La Ratio busca unir "virtud con letras": "Para el logro de este principio fundamental, la Ratio organiza el proceso educativo a través de la unidad, el orden, la gradación de los estudios, la enseñanza activa y participativa, el equilibrio de teoría y praxis, el cultivo de la expresión oral y escrita, la aplicación de los recursos psicológicos para fomentar el interés y la participación, la relación cordial de maestros y discípulos, la colaboración de los familiares, la asimilación, la reflexión y degustación de los conocimientos adquiridos, la unidad y coordinación en la dirección del centro escolar, los medios de vigilancia, suavidad de los castigos el fomento de la responsabilidad de los alumnos, etc."”.

Pero el elemento esencial y común a la espiritualidad ignaciana y a la Ratio studiorum es el cuidado y seguimiento personal del estudiante o cura personalis, que consiste en dar y exigir al discípulo lo que le corresponde de acuerdo con sus posibilidades y su ritmo singular. Implica un conocimiento personal del estudiante y un acompañamiento afectuoso y exigente que le permita alcanzar lo que debe: su realización humana; en términos ignacianos, "el fin para el que fue criado" .

En definitiva, la eficacia educativa de la Ratio studiorum se fundamenta en la coherencia entre sus principios y las estrategias de enseñanza y aprendizaje.

\section{La ratio en la Nueva Granada}

La llegada de los primeros jesuitas a la Nueva Granada coincide con la promulgación de la Ratio studiorum.

Los jesuitas, a diferencia de los "curas doctrineros”, son clérigos regulares con una sólida formación académica. Una vez llegados a tierras de los muiscas, se dieron a la tarea de estudiar su idioma y de evangelizarlos en su lengua ${ }^{10}$.

De esta manera, se crea el Colegio de la Compañía en Santa Fe para la formación de los nuevos jesuitas, la educación de la juventud neogranadina (a petición de criollos y chapetones) y la catequización de los "indios”. La mejor descripción de cómo funcionó en la práctica el Colegio de la Compañía en la Nueva Granada la hace el P. José del Rey Fajardo, S.J., en su estudio "La implantación de la Ratio Studiorum en la Provincia del Nuevo Reino de Granada"11.

Entre sus primeros profesores, el Colegio contó con el P. Alonso de Sandoval, S.J., estudioso y defensor de la dignidad de los pueblos africanos esclavizados (De instauranda aethiopium salute), y con el estudiante Pedro Claver (1580 - 1654), quien santificaría su vida en el servicio a los negros y se convertiría en el "esclavo de los esclavos".

Dada la cualificación de los estudios y el aprovechamiento y avance de sus estudiantes, en 1623 se abre la Academia Xaveriana

\footnotetext{
8 VÁSQUEZ POSADA, Carlos. "La Ratio: sus inicios, desarrollo y proyección”. Tomado de <http:// www.puj.edu.co/pedagogia/documentos/desarrollos.html>

9 Principio y fundamento de los Ejercicios espirituales.

10 Ejemplo de ello es el Diccionario y gramática chibcha del P. José Dadey (1612).

11 Tomado de <http://www.puj.edu.co/pedagogia/documentos/implantacion.html>
} 
en los predios del Colegio-Seminario de San Bartolomé sobre la "Calle de las Aulas" en Santa Fe. En la naciente Universidad Javeriana se comienza a estudiar el pensamiento moderno. De ello dan cuenta el texto Nueva filosofía natural physica specialis et curio$s a^{12}$ y el trabajo del P. Dennis Mesland, S.J., “discípulo de Descartes, quien fue el primero en enseñar estas doctrinas (racionalistas) en tierras americanas”13.

Como datos significativos, hay que recordar que en 1620 el P. José Gumilla, S.J., trajo al país el café, y que en 1738 los jesuitas trajeron la primera imprenta a la Nueva Granada. Una de sus primeras publicaciones fue $E l$ Orinoco ilustrado, del mismo P. Gumilla.

En el marco de la escolástica renovada (esa confluencia tan particular entre la Ratio studiorum, el enfoque suareciano del tomismo y el estudio del pensamiento europeo ilustrado $)^{14}$ se formó la generación de los próceres de la Independencia en un elevado concepto de su dignidad que los llevó a empeñar su vida por nuestra emancipación de España. También en este marco se hicieron desarrollos en diversos campos de la fe, del saber, de la cultura y de la ciencia, entre otros.

De esta manera, la Ratio studiorum se constituyó en la pedagogía y didáctica orientadoras del pensamiento educativo durante la Colonia en el Nuevo Reino de Granada, y no solamente del pensamiento jesuítico, como se podría ver al revisar el estilo desarrollado en los centros de educación de la época.

En definitiva, en la Ratio studiorum se forma la mentalidad escolástica del pueblo co- lombiano. Ésta sigue siendo el referente y el lugar ideológico común a partir del cual se interpretan y resignifican la educación y los demás eventos de la cultura colombiana. Por esto, la Ratio no sólo es la educadora de las generaciones coloniales, sino que determina significativamente la formación de la mentalidad nacional.

La Compañía de Jesús fue expulsada de tierras españolas por Carlos III en 1767 y suprimida por la Bula Pontificia de 1773. De esta forma, concluye la influencia de la Ratio studiorum en la Colonia neogranadina.

\section{La ratio y la mentalidad neoescolástica}

De 1886 a 1930, los conservadores, liderados ideológicamente por monseñor Rafael María Carrasquilla, recuperan la mentalidad escolástica con el objeto de construir un proyecto de nación de corte católico y conservador.

Monseñor Carrasquilla se dedicó a desarrollar la vigencia del tomismo y su influencia política en la organización del Estado. Se inspiró en el conservadurismo del cardenal Mercier y en la Escuela de Lovaina. Su obra está más dirigida a reforzar la ortodoxia católica que a crear un nuevo tomismo. Su objeto es exponer dogmáticamente la escolástica y atacar las corrientes modernistas que desconocen la autoridad de la Iglesia. Defiende la necesidad de una ciencia cristiana contra la concepción moderna de ciencia que niega que Dios es su principio creador e integrador.

\footnotetext{
12 Biblioteca colombiana de filosofía. Bogotá: Ediciones Universidad Santo Tomás, 1988. Transcripción, traducción e introducción de Pedro Nel Ramírez.

13 DEL REY FAJARDO, José. "La implantación del Ratio Studiorum en la Provincia del Nuevo Reino de Granada”. Tomado de <http://www.puj.edu.co/pedagogia/documentos/implantacion.html>

14 El Colegio de San Bartolomé poseía la biblioteca más ilustrada de la época en América, que se convirtió en la Biblioteca Nacional con la expulsión de los jesuitas.
} 
Los regenerados creían que la crisis moral del país se debía a "la enseñanza que se había venido dando en las universidades y a la filosofía que se había venido divulgando desde su cátedra y que era una enseñanza más o menos impía y materialista”" ${ }^{15}$. De aquí la necesidad de entregarle la custodia de la educación a la Iglesia y de volver a una enseñanza desde la guía de Santo Tomás que permitiera contrarrestar el utilitarismo y el sensualismo que habían introducido los benthamistas en la educación. De esta manera, la educación se hace la principal fuente de moralización de la sociedad colombiana.

Por pedagogía neoescolástica se entiende el proyecto educativo que se deriva del tomismo y, más particularmente, de la escolástica renovada en el país. Este proyecto se concreta en un conjunto de saberes y prácticas que se inspiraron en la educación católica y en la Ratio studiorum, en general, y en la obra educativa de Juan Bautista de La Salle, en particular. Su representante más destacado en el país es Martín Restrepo Mejía con su obra Elementos de pedagogía (1892).

Inspirada finalmente en la antropología tomista, la pedagogía neoescolástica orientó oficialmente la mentalidad educativa colombiana hasta los años 30 y cimentó el pensamiento educativo actual. Tal ha sido su influencia en la mentalidad educativa colombiana que podemos decir que no hemos hecho más que una interpretación escolástica de las nuevas corrientes educativas y filosóficas que se han dado en Colombia, incluso de las más alejadas de la religión. No hemos hecho más que escolásticas, como diría Rubén Jaramillo.

Esta pedagogía busca la felicidad del ser humano por medio de la salvación de su alma inmortal y de su realización definitiva en Dios. Para ello, es necesario que el ser humano utilice su capacidad racional y de libre albedrío. Si ésta es "bien” utilizada, no puede entrar en contradicción con la verdad revelada por la teología. Pero, en la práctica, la vivencia de la fe se reduce a la observancia de una serie de prohibiciones y al cumplimiento de los mandamientos. Y esto determina la falta de protagonismo y la pasividad del educando.

Se desprende de esta situación el olvido o menosprecio de lo corporal, pues la prioridad está colocada en la salvación del alma, que es el componente inmortal del ser humano. Este dualismo ha marcado profundamente la autocomprensión que tenemos de nosotros mismos.

“El maestro enseña porque es el que sabe. El niño es un ser que hay que desarrollar, enderezar, corregir como un árbol o un animal. Su alma está concebida para la salvación eterna y para la perfección en el bien”16. Por esto, se debe disciplinar el cuerpo en función de salvar su alma. Hay que someterlo al encierro (internado-convictorio) o hay que castigarlo, cuando fuera necesario.

Así entendido el ser humano, se genera una actitud resignada frente a la vida, pues, lo importante acontece más allá de la muerte en un estado más pleno que el actual. Se deriva de aquí la poca importancia que le da la fe cristiana a los asuntos del mundo terrestre y temporal. La construcción del "Reino de Dios" es una obra espiritual que no tiene que ver con las preocupaciones y trabajos humanos.

Esta concepción del ser humano también genera una actitud irresponsable frente a lo

\footnotetext{
15 JARAMILLO URIBE, Jaime. “La filosofía en el siglo XIX y principios del XX.” En: Análisis (Bogotá) v.23, no. 45, enero-junio, 1987, p. 89-94.

16 QUICENO, Humberto. “Corrientes pedagógicas en el siglo XX en Colombia”. En: Revista Educación y Cultura, n. 14.
} 
social y al futuro común de los seres humanos y del planeta. Se cree que basta con las obras de caridad para resolver los conflictos sociales.

Como la finalidad es acercar al ser humano a la santidad, hay que alejarlo de los males de este mundo: para la doctrina social de la Iglesia del momento y para monseñor Carrasquilla eran el liberalismo y el socialismo ateos.

\section{A modo de conclusión}

Como se ha visto, la educación católica llenó la mayor parte de las expectativas educativas nacionales hasta el siglo XX. De esta manera, propició que la mentalidad (neo)escolástica se convirtiera lentamente en el "modo de pensar" común que está en la base del modo de ser de los colombianos y latinoamericanos. Esta subyace y permite la confluencia de las diferencias ideológicas. Por ejemplo, entre centralistas y federalistas, entre positivistas y románticos, entre liberales y conservadores, entre la derecha y la izquierda.

La escolástica es el inconsciente colectivo nacional; por lo tanto, tiene un carácter social e impersonal, y se transmite por la tradición. Más que una doctrina religiosa, que una ideología o que un método de enseñanza, se convirtió en una pedagogía y en un estilo de vida que han marcado esencialmente el modo de ser de la nación.

Por esto, la pedagogía (neo)escolástica se ve usualmente calificada peyorativamente como “educación tradicional”. Así se le suman todos los errores que se quieren evitar, pues no se ha hecho de ella una valoración crítica que permita identificar sus límites y posibilidades para la educación colombiana. También porque no sabemos qué tanto dependemos de ella en cuanto proyecto de nación.
Hay que rescatarle el hecho de haber formado un alto concepto de dignidad humana en la conciencia nacional y la formación de los hábitos básicos, sobre todo en las clases populares. Un fruto del asistencialismo de la Iglesia fue la educación a muchos colombianos pobres. De esta forma, se ha llenado escasamente el vacío dejado por el Estado en la educación del pueblo colombiano. Pero esta situación también propició la educación para las diferencias sociales. Una era la educación que la Iglesia le daba a las clases pudientes y otra a la mayoría pobre, pero en las dos se abogaba por el mantenimiento de este “orden social”. A veces las primeras financiaban las segundas, y de esta manera se hacía caridad cristiana, pero no justicia social.

En la pedagogía neoescolástica se educaron grandes humanistas y personalidades. La educación neoescolástica de comienzos de siglo XX formó una elite “culta” que logró el reconocimiento de Bogotá como la “Atenas suramericana”, aunque, a la par, se mantenía un alto índice de analfabetismo rural.

La mentalidad escolástica generó una escisión de la conciencia nacional entre la fe y la vida. Se volvió norma que "el que peca y reza empata”. Esto nos ha hecho un país contradictorio. De la misma manera que somos una nación con un alto índice de personas que se dicen religiosas, somos a la vez uno de los países más injustos y violentos del mundo. A nombre de la fe católica y de las "buenas costumbres", los conservadores atizaron las guerras civiles desde el siglo XIX; y para romper los privilegios de la alianza entre la Iglesia católica y el partido conservador, los liberales cometieron las más graves violaciones de los derechos humanos.

Lo peor es que este “orden de cosas”, que mantiene en la indignidad a la mayoría de los colombianos y latinoamericanos, no genera conflicto moral en la conciencia nacional. Justamente porque en nuestra mentali- 
dad común operan una serie de mecanismos para tranquilizar la conciencia y justificarse ante las urgencias éticas.

La escolástica es el referente desde el que se describen y valoran críticamente las ideas y mentalidades filosóficas y educativas en Colombia. Así, la pedagogía neoescolástica sigue siendo el lugar ideológico común mediante el cual se piensa la educación en Colombia: la mentalidad que sustenta y entra en diálogo con las ideas educativas contemporáneas ${ }^{17}$. De esta manera, la neoescolástica ha interactuado en el siglo XX en Colombia con la pedagogía activa (a partir de los años 30), la tecnología educativa (años 50), la pedagogía liberadora (años 60 y 70) y los constructivismos (a partir de los años 80).

Hoy podemos decir que permanecemos en un eclecticismo acrítico ${ }^{18}$ por la confluencia de tendencias educativas con una deficiente asimilación crítica, por la falta de claridad y coherencia del proyecto educativo colombiano y porque la realidad nacional no es el horizonte ni la intencionalidad de las pedagogías que inundan el pensamiento educativo actual. Por esto; el educador colombiano promedio resultó ser un exabrupto: profesores que ideológicamente se consideran constructivistas, pero que en la práctica son conductistas, y que en el fondo son escrupulosamente escolásticos todavía.

Es necesario que nos pensemos, hablando en términos pedagógicos, desde y para nosotros mismos, pues se han invertido muchos esfuerzos tratando de ajustar la realidad educativa a modelos importados. Por esto hay que pensarnos desde categorías y meto- dologías que permitan comprendernos mejor y dar sentido a lo educativo frente a la realidad nacional.

En la base de nuestra manera de interpretar la realidad sigue operando la lógica bipolar escolástica. Esta reduce la realidad a sus extremos y los postula como opuestos entre sí. Extrapolaciones como alma-cuerpo, verdadfalsedad, bueno-malo. Lógica que sigue determinando nuestros criterios epistemológicos, éticos y estéticos, y que nos impide el acceso a comprensiones más globales e integradoras. Lógica que nos impide alcanzar un justo medio razonable que nos permita aceptarnos en medio de nuestras diferencias en lugar de preferir la aniquilación del otro como única salida. Como si la realidad fuera, todavía, en blanco y negro, y no nos hubiéramos dado cuenta de que es en colores.

Concluyendo, cito de nuevo a García Márquez: "Esta encrucijada de destinos ha forjado una patria densa e indescifrable donde lo inverosímil es la única medida de la realidad. Nuestra insignia es la desmesura. En todo: en lo bueno y en lo malo, en el amor y en el odio, en el júbilo de un triunfo y en la amargura de una derrota . . . Tenemos un amor casi irracional por la vida, pero nos matamos unos a otros por las ansias de vivir ... Somos dos países a la vez: uno en el papel y otro en la realidad... Somos capaces de los actos más nobles y de los más abyectos, de poemas sublimes y asesinatos dementes, de funerales jubilosos y parrandas mortales. No porque unos seamos buenos y otros malos, sino porque todos participamos de ambos extremos llegado el caso y -Dios nos libretodos somos capaces de todo" ${ }^{\prime 9}$.

\footnotetext{
17 Ver RAMÍREZ, Edgar. "Posibilidades de la historia de las ideas y de las mentalidades para la filosofía latinoamericana”. En: Cuadernos de filosofía latinoamericana n. 78 - 79. 2000.

18 Eclecticismo acrítico en cuanto que es una decisión consciente, pero sin ningún rigor académico, sino que obedece más a la necesidad inmediata de explicar lo educativo frente a la realidad nacional.

19 GARCÍA MÁRQUEZ, Gabriel. "Por un país al alcance de los niños”. En: Informe de la Misión de Ciencia, Educación y Desarrollo.
} 